\title{
El estilo de la crítica literaria en La máscara, la transparencia*
}

\section{The Style of Literary Criticism in La máscara, la transparencia}

Ioannis Antzus Ramos ${ }^{\text {a }}$

DOI: https://doi.org/10.11144/Javeriana.cl25.eclm

American University, Estados Unidos

iramos@aud.edu

ORCID: https://orcid.org/0000-0002-1831-218X

Recibido: 11 Agosto 2020

Aceptado: 08 Marzo 2021

Publicado: 20 Agosto 2021

\section{Resumen:}

En este artículo estudiamos el estilo de la crítica literaria en La máscara, la transparencia (1975), la gran obra ensayística de Guillermo Sucre (Venezuela, 1933). Para llevar a cabo este análisis partimos de su propia concepción de la crítica y nos centramos en dos aspectos fundamentales: 1) la dialéctica entre el movimiento y la fijeza, y el intento de convertir el texto crítico en un absoluto verbal, y 2) la conciencia de que está tratando con palabras (y no con cosas), lo que da lugar a una actitud de pasión y de crítica con respecto a la propia escritura. Ponemos así de manifiesto cómo los postulados críticos de los que parte el autor permean su propia escritura ensayística.

Palabras clave: La máscara, la transparencia, Guillermo Sucre, crítica literaria, literatura venezolana, ensayo hispanoamericano.

\begin{abstract}
:
In this article I study the style of literary criticism in La máscara, la transparencia (1975), the collection of essays by Guillermo Sucre (Venezuela, 1933). To undertake my analysis I have in mind Sucre's conception of literary criticism and I focus on two main aspects: 1) The dialectics between movement and stillness (fijeza), and his attempt to turn the critical text into a verbal absolute, and 2) the conscience that he is dealing with words (and not with things), which leads to an attitude of passion and criticism towards his own writing. In my analysis I point out how the critical postulates of Sucre pervade his own literary expression.
\end{abstract}

Keywords: La máscara, la transparencia, Guillermo Sucre, literary criticism, Venezuelan literature, Hispanic American essay.

Guillermo Sucre (Venezuela, 1933) pensaba que la crítica literaria debía recrear la vivencia imaginaria y verbal de la obra-objeto en una nueva experiencia creativa. Para ello, el crítico tenía que analizar la creación, pero también tenía que participar en ella, es decir, debía alcanzar la máxima saturación posible entre su propia mirada y el texto estudiado. Cuando se producía la coincidencia plena entre el sujeto y el objeto, el crítico lograba detener momentáneamente el sentido de la obra y lo volvía presencia en una nueva expresión verbal. Al buscar esta concomitancia, la escritura de Sucre encontró en el ensayo literario su cauce ideal, pues, como afirma Pozuelo-Yvancos, es en este género donde "se hacen solidarios los espacios del sujeto y del objeto de la representación, creando, con la invención, un espacio de creación imaginaria, que se sostiene en su propia verosimilitud" (184). ${ }^{1}$

Es esta continuidad que la crítica de Guillermo Sucre busca establecer entre lo mirado y la mirada lo que determina el carácter de su escritura ensayística. En primer lugar, nuestro autor concibe que la obra es un sistema coherente de relaciones cuya significación está controlada por la figura del autor. Si el conjunto de los escritos de una misma persona presenta unas características comunes y una cierta homogeneidad, y si la escritura crítica tiende a "reasumir y reanimar" el sentido de la obra, es evidente que el propio ensayo de interpretación estará estructurado también como un sistema. Ya que pretende ser la recreación de una experiencia creativa coherente, la escritura crítica tiende a reproducir esa misma coherencia: en ella, por lo tanto, la ruptura se resuelve en una continuidad y el lenguaje tiende a volverse una imagen o un cuerpo total.

Notas de autor

\footnotetext{
a Autor de correspondencia. Correo electrónico: iramos@aud.edu
} 
En segundo lugar, Sucre es consciente de que la fusión entre el sujeto y el objeto que debe darse en toda crítica adecuada es simultáneamente relativa y absoluta. La contingencia de esa unión viene determinada por el hecho de que tanto la mirada que el crítico vierte sobre la creación literaria como el propio lenguaje y el sentido de la misma tienen una dimensión histórica, es decir, variable. Pero el hecho de que Sucre reconozca la relatividad de toda crítica no implica que en sus ensayos no trate de alcanzar el límite propuesto por la obra. En ellos, él busca que el proceso de superposición crítica se dé con la máxima saturación posible: desde su perspectiva parcial quiere alcanzar la significación igualmente puntual de la creación que estudia, pero esa fusión circunstancial debe ser absoluta. En la práctica crítica de Sucre, la subjetividad del exegeta busca la objetividad de la obra y el texto es el resultado del encuentro entre esas dos entidades (intérprete y creación) que, aunque están girando y cambiando continuamente, coinciden en un instante de plenitud. Los ensayos críticos de Sucre son por eso una suerte de work in progress: en ellos asistimos a la dramatización del proceso cognitivo, es decir, a un asedio incesante en el que la mirada del sujeto busca aprehender el sentido propuesto por la obra. Su crítica, por lo tanto, no expresa simplemente una significación previamente establecida, sino que nos hace testigos de ese instante erótico en el que los ojos del exegeta inventan y descubren en el presente de la escritura el cuerpo fugitivo de la creación. ${ }^{2}$

\section{La crítica como sistema. La dialéctica entre el movimiento y la fijeza}

Guillermo Sucre concibe la obra literaria como un sistema coherente, y piensa que el propio texto crítico tiene que reproducir esa homogeneidad. Por eso, sus ensayos están gobernados por una serie de relaciones rítmicas que buscan hacer evidente la unidad de las diferentes partes (de la escritura crítica y de la obra de referencia, simultáneamente) y la del texto en su conjunto. La escritura de Sucre tiende a controlar la proliferación incesante del lenguaje y trata de que el ensayo se cristalice en una imagen. Para lograr esto, intenta conjurar el carácter sucesivo de la expresión escrita a favor de la simultaneidad y el éxtasis, y vigila el avance del discurso para que cualquier ruptura o interrupción del mismo se resuelva en continuidad. Por eso, su crítica presenta un vaivén "entre el movimiento y la fijeza" 3 o entre "la dispersión y la tensión" (Sucre, "Entretextos" 53) que es característico también de la escritura de Octavio Paz. Como nuestro autor afirmaba, a propósito de Piedra de Sol, sus propios ensayos son "un discurrir y una continua reiteración", es decir que "su movimiento es extático: lo uno se disuelve en lo dual, lo cual se concentra en lo uno" (Sucre, La máscara 223; $1 .{ }^{a}$ ed.). ${ }^{4}$ Sucre piensa que "todo texto, y no sólo el universo, podría definirse en última instancia como una 'metamorfosis de lo idéntico"' (La máscara 431; 1. a ed.); por eso, la figura que mejor condensa el carácter de su escritura es la metáfora por contigüidad que él estudió en la obra de Paz. En ella, y también en los ensayos de Sucre,

\footnotetext{
los fragmentos se relacionan no tanto por semejanza o contraste previos, sino por contigüidad: están en un mismo espacio, se encuentran o se rechazan, desaparecen o se prolongan en otros; es a través de este movimiento como se van constituyendo en una verdadera trama. (La máscara $234 ; 1 .^{a}$ ed.) ${ }^{5}$
}

Nuestro autor busca convertir la escritura crítica en un texto, es decir, en un tejido que enlace los diferentes hilos y concluya en una pieza armónica que sea capaz de reproducir la continuidad de la obra. Pasamos seguidamente a estudiar los mecanismos mediante los cuales Sucre logra esto. Primero, abordaremos aquellos que tienden a establecer la continuidad en la frase o en el párrafo y, después, los que tienden a estructurar el discurso a un nivel más general.

$\mathrm{Al}$ acercarnos a los ensayos de La máscara, la transparencia, lo primero que llama la atención es la intensidad y la sensación de éxtasis que los recorre. La fluencia de la escritura no permite la interrupción, y la novedad y la diferencia se resuelven en analogía y en continuidad. Como el discurso es un manar que no cesa, el lector se ve envuelto por un ritmo incesante en el que lo nuevo parte de lo ya mencionado y lo diferente es también semejante. Contribuye a la creación de este efecto, además, el hecho de que sus ensayos nos muestran el proceso 
de un pensamiento pensándose. Como asistimos a la dramatización de una reflexión en presente, el discurso avanza a través de profundizaciones críticas sobre lo ya mencionado. Se da algo por sentado y a partir de ello se produce otro acceso crítico: la intensificación se prefiere a la ruptura y el nuevo punto de vista surge del anterior. De este modo, la escritura de Sucre (como él decía a propósito de Borges) se puede caracterizar como "un juego dialéctico entre [...] un síy un pero" en el que "los sucesivos peros no funcionan como simples atenuantes: al oponer una resistencia al es (al sî), crean una nueva perspectiva" (La máscara 290; 1. ${ }^{a}$ ed.). ${ }^{6}$ En los ensayos de Guillermo Sucre, este juego se da a través de toda una serie de mecanismos que detienen momentáneamente el discurso para emprender, a partir de la pausa, una nueva profundización del mismo. En ellos, como hemos dicho antes, lo diferente se resuelve en semejanza y el progreso queda limitado por una estructuración coherente: "Lo uno se disuelve en lo dual, lo cual se concentra en lo uno" (La máscara 222, 1. ${ }^{\mathrm{a}}$ ed.).

La interrupción prepara un nuevo advenimiento, la fijeza es móvil y el movimiento se detiene: así, la escritura se convierte en un sistema imbricado de relaciones que se tiende a cristalizar en una imagen total. El dispositivo más simple que confiere a los ensayos de Sucre esa dialéctica característica entre la dispersión y la tensión es la yuxtaposición entre dos sintagmas u oraciones. En este sentido, hay que mencionar el empleo de los dos puntos, que sirve para establecer una equivalencia entre diferentes términos u oraciones, de manera que el contraste o la novedad, sin dejar de serlo, se resuelve en analogía. Como ejemplo de esto podemos mencionar los títulos de algunos de los ensayos de nuestro autor. Su texto "Ramos Sucre: la pasión por los orígenes" está estructurado en cuatro apartados, que se titulan respectivamente "La perfección: la fatalidad", "El sentido: la paradoja", "El mal: la historia", "La verdad: las máscaras". Igualmente, dentro de La máscara, la transparencia nos encontramos con los siguientes ensayos: "Vallejo: inocencia y utopía", "Borges: marginal, central", "Paz: la vivacidad, la transparencia", etc. Estos encabezamientos proponen la semejanza a partir de la divergencia y muestran además la igualdad que Sucre establece entre los autores y las experiencias que toman cuerpo en sus obras. Las mismas equivalencias se aprecian dentro del propio discurso, en el que muchas frases se aclaran a través de otras que están en aposición y también que se encuentran marcadas con dos puntos. De entre los innumerables fragmentos donde esto sucede podemos citar, por ejemplo, este: "Pero el ideal de justeza expresiva, en Huidobro, es sólo el comienzo de otro intento quizás más ambicioso: hacer del poema una arquitectura que se construye desde sí misma" (La máscara 103; 1. ${ }^{\mathrm{a}} \mathrm{ed}$.). O este otro: "Como se ve, no tanto un nuevo lenguaje como una nueva manera de articularlo: lo fragmentario y lo total, la simultaneidad también, la superficie plana y la profundidad" (La máscara $103 ; 1 .^{a}$ ed.).

Este recurso estilístico coexiste con el de la adición o "agregación", que Miguel Gomes destacaba como "el método de exposición preferido" " de La máscara, la transparencia. El profesor Gomes estaba en lo cierto, pues el estilo de esta obra, y, en general, el de la ensayística de Sucre, es un proceso permanente de concreción crítica que avanza completando lo ya expresado. Ahora bien, esta tendencia que consiste en problematizar las propias conclusiones y en ahondar sobre lo establecido se lleva a cabo a través de diferentes mecanismos, y todos ellos contribuyen a conferirle a la escritura de Sucre el ritmo incesante que la caracteriza. A este respecto, hay que mencionar las expresiones aditivas introducidas normalmente por adverbios como además, también, igualmente, etc. En estos casos, la segunda proposición viene a completar lo ya dicho y a introducir una nueva perspectiva. Así, por ejemplo, nuestro autor afirma en un ensayo sobre Vallejo:

De nuevo, consagración de lo elemental, pero también, ahora, como una fuerza histórica. Se comprende que la plenitud que evocan estos poemas es la expresión de un fervor revolucionario. Es obvio, además, que la marginalidad coincide con la concepción marxista de Vallejo y con su experiencia de militante comunista. (La máscara 151; 1. ed.)

Lo mismo se aprecia en este fragmento en el que nuestro autor está escribiendo sobre la poesía de Lezama Lima: "Esta idea es central no sólo por lo que ella contiene en sí misma: vale decir, la visión afirmativa que Lezama tiene de la literatura. Lo es también, y sobre todo, por la desmesura de esa visión" (La máscara 181; $1 .{ }^{a}$ ed.). Como se ve en ambos ejemplos, a partir de una idea establecida se produce un nuevo desarrollo 
que le sirve al crítico para acercarse al objeto y para que su insight logre la máxima precisión. Esta dialéctica entre la fijeza y el movimiento se aprecia también en el empleo de fórmulas contraargumentativas del tipo “es..., pero...", o "no es... es...”. Así tenemos, por ejemplo: “Es cierto que en algunos poemas se trata más de la comprobación de una ausencia a la vez que el enfrentamiento con una actualidad desolada [...]. Pero con mayor frecuencia la memoria adquiere el sentido de la ubicuidad" (La máscara 143; 1. ${ }^{\mathrm{a}}$ ed.). Y también:

No es la visión de la unidad, sin embargo, lo que prevalece en la obra de Parra. Lo que en ella prevalece es una voluntad disociativa y aun de aniquilamiento, lo cual se acentúa en sus textos más recientes y casi actúa como una fuerza ajena al autor. $(\text { La máscara 313; 1.a ed. })^{8}$

También con estas fórmulas, lo vemos, la novedad es el resultado de la continuidad o bien surge de ella.

El mismo efecto se logra con las anteposiciones del atributo o predicativo. En estos casos, Sucre inicia la oración con un adjetivo que tiene la función de resumir un contenido previamente expuesto y se sirve de él para proponer una nueva progresión del discurso. Me estoy refiriendo a casos como este: "Abstracta, no se trata, sin embargo, de una poesía de conceptos, sino de pensamiento" (La máscara 238; 1. ${ }^{\mathrm{a}}$ ed.). O este otro: "Dramático, el monólogo del poema es igualmente vertiginoso: flujo de imágenes, motivos verbales, juegos del lenguaje, conceptos, confesiones" (La máscara $123 ; 1 .^{\mathrm{a}}$ ed.). Otras veces, el término que se antepone está formado por un sintagma nominal: "Plenitud desterrada y lucha tenaz contra la muerte, lo imaginario en Sánchez Peláez es también una sabiduría para enfrentarse a la complejidad del mundo" (Sucre, La máscara 303; 2. ed.). Y también: "Poemas sobre una guerra muy concreta, España, aparta de mi este cáliz no es un libro de circunstancias, como otros sobre el mismo tema de la guerra civil española” (La máscara 153; 1. a ed.). ${ }^{9}$ En todos estos ejemplos, como se ve, los adjetivos o los sintagmas antepuestos resumen un contenido expresado anteriormente o lo anticipan, y a partir de él emprenden un nuevo avance, lo que contribuye a generar ese vaivén característico entre el movimiento y la fijeza. Es frecuente, además, que este recurso coincida con un cambio de párrafo, en lo que parece un giro ya abiertamente lúdico e irónico por parte del autor. En esos casos, la ruptura del párrafo contrasta con la continuidad del discurso, por lo que, al tiempo que se genera sorpresa en el lector, el avance de la enunciación se vuelve dependiente de lo mencionado con anterioridad. Un ejemplo llamativo de esto último lo hallamos en el capítulo de La máscara dedicado a la obra de Octavio Paz:

De ahí que el último texto del centro (final del poema) no sólo sea la condensación — recurrencia, valoración y resumende la temática del lenguaje, sino también de la erótica. Ambas, pues, finalmente se fusionan.

Pero se fusionan no sin antes enfrentarse en un contrapunto que hace aflorar la tensión que subyace a todo lo largo del poema y que Paz resume en esta fórmula. $\left(232 ; 1 .^{\mathrm{a}}\right.$ ed.)

En este ejemplo, como es fácil de apreciar, el cambio de párrafo no se corresponde con la interrupción del discurso. Por el contrario, la pausa sirve para retomar la misma idea con una fuerza renovada y la ruptura aparente se resuelve en continuidad. Además, al principio del segundo párrafo vemos una estructura contraargumentativa que mantiene la continuidad con respecto a lo afirmado previamente. Otro buen ejemplo lo tenemos en el ensayo "La poesía: una fértil miseria”, que está dedicado a la poesía de Álvaro Mutis. En él se indica:

Voces malditas o inocentes, víctimas o cómplices, todas ellas van formando el enjambre sonoro, oscuro y también luminoso, de muchos de los poemas de Mutis. Son un conjuro y a la par una obsesión: si Mutis las escucha no es para convertirse en esa identidad un tanto pretenciosa que ahora llaman "testigo", sino por pura fascinación y hasta verdadera identificación.

Voces anónimas. Voces también de personajes anónimos que hablan de sus oficios. Ni prestigiosos ni anodinos, esos oficios se sitúan, sin embargo, en una cierta marginalidad: introducen en la opacidad lo imprevisible. (La máscara 369; 1. ${ }^{\mathrm{a}}$ ed.)

Como vemos, la separación entre los párrafos se podría haber suprimido, pues el tema del segundo insiste sobre lo señalado por el primero. Además, al comienzo del nuevo parágrafo aparece una estructura que permite recolectar lo dicho en el anterior ("Voces anónimas") y, a partir de ello, proponer un progreso ("Voces también...”). Estas interrupciones "arbitrarias" del discurso son visibles también a un nivel oracional, 
y contribuyen a conferir a la escritura esa alternancia característica entre el reposo y la continuidad. Es lo que se aprecia en este ejemplo, en el que vemos además la fórmula contraargumentativa que hemos mencionado más arriba: "La sobreabundancia puede ser en Lezama una gracia (en el sentido teológico) o un don. No es lo que importa. Importa más saber que él la asume como una manera de existir" (La máscara 197; 1.a ed.).

Otro recurso que tiene consecuencias parecidas es el procedimiento al que vamos a llamar de diseminación y recolección. Este mecanismo consiste en recopilar una serie de asuntos aparentemente dispersos tratados hasta un momento dado y plantear a partir de ellos un avance de la enunciación. Se trata, también aquí, de establecer una continuidad en la escritura y de hacer que lo nuevo surja como prolongación de lo precedente. Un ejemplo de esta técnica lo tenemos en el ensayo sobre Vallejo incluido en La máscara, la transparencia. Una vez estudiadas en él una serie de ideas por separado, Sucre las reúne para extender el discurso a partir de ellas: "Penuria existencial y social, desposesión del cuerpo y del mundo, dolor que lo trastoca todo, la enajenación penetra inevitablemente hasta la conciencia del hombre. Se produce, así, el desdoblamiento del sujeto poético" (148; $1 .^{\mathrm{a}} \mathrm{ed}$.). Un caso semejante aparece en el estudio titulado "Lezama Lima: El logos de la imaginación”. Después de tratar varias cuestiones de una manera dispersa, Sucre las agrupa para emprender un nuevo desarrollo: "Lo estalactito: agua grabada: mano con hojas (escritas) de nieve: el poema es fijeza" (200; 1. ${ }^{a}$ ed.). En el mismo ensayo encontramos otro ejemplo de este mismo recurso: "Cuerpos visibles: relaciones invisibles creadas por el poeta: también en la obra de Lezama nos encontramos con lo que podríamos denominar, con palabras suyas, “lo semejante ancestral'” (201). ${ }^{10}$ Es así como nuestro crítico consigue establecer una relación entre aspectos diversos de una misma obra y logra que la continuidad se imponga sobre la ruptura.

A generar el ritmo incesante y la dialéctica entre el movimiento y la fijeza se contribuye también a la aparición de elementos inesperados. Con ellos se crea una expectativa que mantiene viva la intensidad de la escritura y que enfatiza la unidad del discurso. Esto lo logra Sucre mediante el empleo de citas textuales en posición inicial o sin previo aviso. Al introducir fragmentos literales de una manera sorpresiva, Sucre nos introduce de golpe en la fluencia de la enunciación y consigue asimilar la novedad al ritmo de la escritura. El capítulo titulado "La metáfora del silencio" empieza así: "Enamorado del silencio, al poeta no le queda más recurso que hablar'. Ni inconsecuencia ni simple paradoja, mucho menos desilusión: esta frase de Paz encierra, más bien, otro sentido, que es una doble metáfora" (La máscara 339; 1. ed.). Vemos cómo el punto desde el que comienza a tejerse el discurso crítico es la frase exacta del autor mexicano: la irrupción y la sorpresa son el punto de partida para el despliegue de la escritura. De manera semejante, en el capítulo titulado "Paz: la vivacidad, la transparencia", se copia sin previo aviso la estrofa inicial del poema "Piedra de Sol" (1957) y solo después de esa irrupción se advierte: "Este pasaje es el comienzo de 'Piedra de Sol. Es sabido que este poema tiene como trasfondo diversas significaciones míticas" (La máscara $221 ; 1 .{ }^{\mathrm{a}} \mathrm{ed}$.). ${ }^{11}$ Un recurso menos frecuente, pero con consecuencias similares, lo constituye la aparición repentina de frases cuyo sujeto se deja voluntariamente sin expresar. El caso más evidente lo tenemos al principio del ensayo que acabamos de citar sobre la obra de Paz. Hablando sobre "la vivacidad", Sucre indica:

\footnotetext{
No se trata tan sólo de un punto de vista teórico o filosófico, al margen de su creación; constituye, por el contrario, el impulso profundo de toda su obra poética. Una y otra vez aparece a lo largo de esa obra: "En las fronteras del ser y el estar, / una vida más vida nos reclama”, escribe en 1948: "busco una hora viva como un pájaro”, en 1958. Igual perspectiva aparece en Ladera Este (1969). Es un poema escrito en la India y evoca una de sus ciudades sagradas; el personaje central es un sadú, asceta vagabundo que vive abstraído del mundo en pura contemplación de la eternidad. (La máscara 207; 1.a ed.)
}

En este ejemplo vemos cómo de repente se nos comienza a hablar de un poema como si conociéramos ya su título. Ello genera sorpresa en el lector y mantiene la sensación extática y la continuidad del discurso.

Además de los mecanismos que hemos visto hasta ahora, todos los cuales tienden a controlar la dispersión de la escritura y a crear un vaivén característico entre el movimiento y la fijeza, Sucre utiliza otro tipo de procedimientos que confieren coherencia al ensayo en su totalidad. Uno de ellos consiste en la estructuración 
de los ensayos mediante hitos o claves conductoras ${ }^{12}$ que establecen una igualdad entre diversos momentos del discurso. En el subcapítulo "Los números severos y apostólicos", que pertenece al estudio dedicado a la obra de Vallejo, la presencia de estas "rimas" es claramente visible. El apartado al que nos estamos refiriendo comienza así: "Trilce: palabra inventada" (La máscara 139; 1. ed.). En la página siguiente se repite lo mismo: "Ya lo decíamos antes: Trilce es palabra inventada" (141). Un poco después se apunta: "Ahora bien, Trilce es vocablo que encierra una significación numérica” (141). Y al comienzo del párrafo siguiente se insiste en lo dicho para propiciar un nuevo comienzo: "Trilce, como vocablo, encierra, en verdad, una significación numérica" (141). En el mismo ensayo tenemos otro caso semejante. Después de esta serie de alusiones al título de la obra más vanguardista de Vallejo, Sucre indica: "El tres vallejiano, sin embargo, no es tanto una síntesis como su búsqueda: una posibilidad siempre abierta, una dimensión nueva por encontrar" (141). Y a continuación señala: "El tres, por otra parte, es la posibilidad de un nuevo tiempo; no simplemente un futuro, sino un tiempo total que encierre y a la vez trascienda 'las tres tardas dimensiones" (142). Más adelante, cuando ya creíamos olvidada la referencia al tres, esta vuelve a aparecer: "El tres, decíamos, es la cifra dominante en Trilce: ello se hace perceptible hasta por el ritmo ternario de los temas del libro" (145). Este rasgo que, como vemos, aparece en repetidas ocasiones en el ensayo sobre Vallejo, está también presente en otros trabajos contenidos en La máscara. Así, por ejemplo, en el estudio sobre Vicente Huidobro, Sucre indica: "No es sino en los libros inmediatamente posteriores donde el lenguaje alcanza a unir la precisión con la intensidad; en ellos se cumple, además, otra alianza más importante: el pensamiento es la forma misma” (102; 1. ${ }^{\mathrm{a}} \mathrm{ed}$.). Tres páginas después, se retoma la misma frase para prolongar sus implicaciones: "El pensamiento se hace forma, o es la forma misma. Así también la experiencia del lector, como tal, ha de ser una experiencia formal” (105). Un ejemplo más aparece en el apartado dedicado a Alejandra Pizarnik en el mismo libro. En un momento dado el autor afirma: "El infierno musical: título irónico y aun cruel, pero exacto. Decir que en él ya está prefigurado su suicidio [...] es decir mucho y muy poco" (362). En la página siguiente, Guillermo Sucre recupera la misma frase para insistir sobre algo que había quedado pendiente entonces: "El infierno musical, dije, es un título irónico y aun cruel, pero exacto: nos está hablando de la muerte en términos estéticos” (363). ${ }^{13}$ Con estas recurrencias dentro del discurso se enfatiza el vaivén entre la dispersión y la tensión, el progreso de la enunciación da la impresión de interrumpirse y se genera una sensación extática que convierte (o tiende a convertir) el ensayo en un sistema cohesionado, en una imagen total.

Otra vía que emplea Sucre para hacer de su escritura una trama coherente consiste en estructurarla de un modo binario. Así, en el ensayo sobre Vallejo, Sucre indica que España, aparta de mí este cáliz no es "el libro de ningún cambio personal, sino el de una transfiguración y el de una revelación" (La máscara 153; $1 .^{\mathrm{a}}$ ed.). ${ }^{14}$ A partir de estos dos términos, se organiza lo que resta del escrito: primero, se trata de la transfiguración en sus diversas formas y, después, de la revelación. Con este mecanismo también nuestro crítico logra controlar la proliferación del lenguaje y de la enunciación, y convertir el texto en un cuerpo homogéneo.

En lo que concierne a esta búsqueda de coherencia y continuidad, hay que decir asimismo que muchos de los ensayos de nuestro autor tienen una estructura circular. A veces, en efecto, Sucre remite al principio desde el final de sus escritos, con lo que frena el avance del discurso y lo convierte en un espacio conexo y uniforme. Así, por ejemplo, cuando nos aproximamos al término del capítulo sobre Lezama Lima, Sucre regresa a una referencia citada al comienzo. Entonces, nuestro autor afirma: "Hay un apólogo de Pascal al que Lezama alude en uno de sus ensayos y que es, en este sentido, revelador: la historia del náufrago que es recibido como el rey desaparecido y decide obrar como tal, sabiéndose impostor" (La máscara 191; 1. ${ }^{\mathrm{e}}$ ed.). Páginas más adelante, cuando ya se acerca al final, dice Sucre:

¿No regresamos de algún modo, en este poema, al apólogo de Pascal, ya citado al comienzo? En todo caso, es significativo que la justicia de que se habla en él esté signada por lo que aparentemente la contraría y aun la niega: la bastardía, el regicidio, el disfraz, la parodia. (La máscara 205; 1. ${ }^{\mathrm{a}} \mathrm{ed}$.) 
De la misma manera, Sucre explica los últimos poemas de Huidobro a partir de una frase que este autor había empleado en los inicios de su obra, con lo que el círculo (de la escritura crítica y de la obra, simultáneamente) se cierra:

Es significativo, por su parte, que Huidobro casi al final de su labor creadora regresara no al "mensaje" sino a las palabras; volver a ellas, repetirlas, aislarlas, combinarlas: de este modo redescubría el lenguaje, no lo inventaba; aun las imágenes podían ser excluidas (al menos en su obsesión creacionista). Me parece que así intentó realizar algo que ya había intuido casi al comienzo de su obra. En efecto, en uno de sus primeros textos de estética ("La Poesía”, 1921), escribía esta frase, quizá más memorable que otras suyas inclinadas a la desmesura (¿demiúrgica?): "La poesía es el vocablo virgen de todo prejuicio; el verbo creado y creador, la palabra recién nacida. Ella se desarrolla en el alba primera del mundo. Su precisión no consiste en denominar las cosas, sino en no alejarse del alba”. (La máscara 127; 1 a $^{\text {ed.) }}$

Asimismo, al poco de comenzar el ensayo sobre Octavio Paz contenido en La máscara, Guillermo Sucre apunta lo siguiente:

A través de toda su obra persiste, en efecto, la pregunta que se hace en la nota preliminar de El Arco y la Lira (1956): "¿No sería mejor transformar la vida en poesía que hacer poesía con la vida?; y la poesía ¿no puede tener como objeto propio, más que la creación de poemas, la de instantes poéticos?". (La máscara 209; 1.ed.)

Y ya más adelante, en el último párrafo —última línea - del escrito, se concluye contestando a esa pregunta: "La aparición del mundo — del mundo original, se entiende - implica la desaparición del lenguaje y de la poesía. Vivir la poesía: escribir el mundo" (La máscara 236; 1. ed.).

Todos los recursos formales que hemos visto hasta ahora tienden a enfatizar la continuidad en el interior del discurso y a convertir la escritura en un absoluto verbal. Esta búsqueda de continuidad se aprecia también, por supuesto, en la manera de leer las obras literarias. A este respecto, debemos destacar que Sucre establece constantemente analogías y diferencias entre segmentos de la escritura de un mismo autor que ponen de manifiesto la coherencia de sus creaciones. Así, en su estudio sobre Rubén Darío, por ejemplo, enlaza un verso del poema "Filosofía" ("Saber ser lo que sois, enigmas, siendo formas") con uno del "Coloquio de los centauros", texto al que se había referido anteriormente ("toda forma es un gesto, una cifra, un enigma”) ( $L a$ máscara 43-44; $1 .^{\mathrm{a}} \mathrm{ed}$.). Un poco después, en el mismo ensayo nuestro crítico pone de manifiesto otra relación: "Al mundo de la plenitud elemental que Darío evoca en 'Filosofía' corresponde, pero como una réplica, el mundo de la conciencia dividida que se desarrolla en el poema 'Lo fatal'” (La máscara 44; 1. ed.). En la visión de Guillermo Sucre, ya sea a partir de la semejanza o de la alteridad, la obra (y también, en consecuencia, la propia escritura del crítico) es el espacio de la correspondencia y de la continuidad. ${ }^{15}$

Los vínculos que Sucre destaca entre diferentes partes de una misma creación pueden apreciarse también a un nivel más amplio. Así como la obra es un espacio coherente limitado por la función-autor, el reino de la literatura es un entorno demarcado por la visión del crítico. ${ }^{16}$ En los ensayos de Guillermo Sucre los textos de un autor dialogan con los de otros creadores, de manera que todos ellos se encuentran en un mismo marco de relaciones. Los escritos contenidos en La máscara presentan multitud de comparaciones de este tipo, y un buen ejemplo de ellas lo tenemos cuando Sucre señala los parecidos ("a semejanza”) y las diferencias ("pero") entre el Narciso del autor de Paradiso y el de dos escritores franceses:

A semejanza con el de Valéry, el Narciso de Lezama también muere, pero esta muerte no es la negación sino la necesaria expansión de la conciencia individual. A semejanza con el de Gide, el de Lezama se identifica con el universo, pero sacrificando su yo, su imagen. $\left(193 ; 1 .^{\mathrm{a}} \mathrm{ed} .\right)^{17}$

También podemos citar los paralelos que nuestro autor establece entre Lugones y Laforgue:

Como él, también Lugones penetró en el mundo de los seres lunáticos: no sólo los literarios [...], sino sobre todo los de la vida cotidiana, contemporánea [...]. Pero mientras en Laforgue ese descubrimiento parece estar ligado a una experiencia poética personal, en Lugones incluso por la evolución general de su obra, tiene mucho de elaboración sin consecuencias" (La máscara $59 ; 1 .^{a}$ ed.) 
En otras ocasiones, el vínculo se establece por contraste con un autor y por afinidad con otro: "A diferencia de Huidobro, que sólo se valió de la combinación de diferentes caracteres tipográficos, Tablada, como Apollinaire, emplea las formas manuscritas" (La máscara 91; 1. ${ }^{a}$ ed.). Sucre, además, no renuncia a establecer comparaciones con otras artes. Así, indica que la descripción del fin del mundo en Vallejo se cumple "con la fuerza sobrecogedora de un Goya" ( La máscara 155; 1. ${ }^{a}$ ed.) o que Herrera y Reissig "está más cerca del expresionismo que del impresionismo" (La máscara 54; $1 .{ }^{\mathrm{a}}$ ed.). ${ }^{18}$ De este modo, no solo el ensayo crítico (y la obra-objeto), sino también el conjunto de ensayos (y las distintas obras) establecen entre sí relaciones de afinidad y oposición, y tienden a devenir una imagen total que coincide con el libro en su conjunto.

[T2]Una matemática expresiva

El hecho de que Sucre trate de convertir sus ensayos en un tejido coherente de relaciones capaz de reproducir la continuidad de la obra-objeto implica que tiene conciencia del lenguaje, es decir que se sabe plenamente situado en el espacio de las palabras. En efecto, que sus textos estén surcados de relaciones rítmicas que tienden a resolverse en un cuerpo total supone que concibe la escritura como una "matemática expresiva" en la que (como dice a propósito de Ramos Sucre) "las palabras se combinan entre sí según su propia necesidad interna, siguiendo un principio constructivo autónomo" (Sucre, "Ramos" 18). Puesto que el lenguaje no es un simple medio para comunicar un pensamiento previo, las ideas de Sucre nacen y se ordenan de acuerdo con las estructuras de la sintaxis, lo que contribuye a controlar el discurso y a conferirle el ritmo que le caracteriza. Además, al reconocer y enfatizar el carácter sígnico de la escritura, Sucre pone de manifiesto el vacío que sostiene a las palabras. Si los vocablos no imitan el estilo "copioso de la realidad", sino el de "la imaginación" o "el deseo" (Sucre, "Ramos" 18), ${ }^{19}$ solo pueden surgir del reverso que los constituye más profundamente: el silencio, la ausencia de lenguaje. Por eso, su escritura resulta — como él afirmaba a propósito de Muerte sin fin (1939) - una "victoria en el vacío", es decir, "una arquitectura no simplemente rigurosa, sino de rigor y de claridad, detrás de la cual no hay nada" (La máscara 300; $1 .^{a}$ ed.). Esto supone asimismo que Sucre presenta una doble actitud de pasión y de crítica con respecto al lenguaje. Al enfatizar la materialidad de la escritura, nuestro autor revela al mismo tiempo su vacuidad; en ello, sin embargo, no hay que ver un rechazo del lenguaje, sino un intento por depurarlo. Al "poner el acento en la palabra como significante" no trata "de arruinar la significación, sino de purificarla: hacer que las palabras recuperen su inocencia para que el sentido encarne de veras en ellas" (La máscara $127 ; 1 .^{\text {a }}$ ed.). ${ }^{20}$

A lo largo de sus ensayos nuestro autor marca deliberadamente (y con cierta ironía, a veces) que su pensamiento se ajusta a las estructuras formales del lenguaje. Esto se aprecia, por ejemplo, en la distribución binaria de las ideas de la que antes hablamos. Me estoy refiriendo a fragmentos como este, que Sucre escribe en un ensayo dedicado a la obra de Ramos Sucre:

Aun sus confesiones son más inclementes e iracundas. Inclemencia: "Imagino constantemente la sensación del padecimiento físico, de la lesión orgánica”. Iracundia: "Mi alma es desde entonces crítica y blasfema; vive en pie de guerra contra todos los poderes humanos y divinos". (Sucre, "Ramos" 30)

O también a este otro:

La actitud de Machado, ya lo hemos dicho, no es aislada; representa una cierta perspectiva del arte. Machado no comprendía dos cosas cardinales del arte contemporáneo. Por una parte, que hubiese una sucesión (iqué lógica!) de presentes que ni siquiera luchan contra el discurrir temporal: son sólo presencias, están allí, los vivimos, por su fulgor reencontramos el mundo. Por la otra, y como consecuencia, que el tiempo del poema no coincida con el de la historia - fugacidad y progresión lineal a la vez-. (La máscara $386 ; 1 .^{a}$ ed. $)^{21}$

En estos casos, lo vemos, las ideas se disponen a partir de una combinatoria formal precisa, con lo que se ve claramente que se ajustan al modo de ser de la sintaxis y no al de "la realidad". Esta estructuración permite además controlar la progresión del discurso, y que la nueva información se origine y dependa de la ya mencionada. 
Además, al concebir la escritura como una trama coherente y superficial de signos que no remite a ningún otro lugar, Sucre pone de relieve el carácter material de la misma. Esto se advierte, por ejemplo, cuando plantea la posibilidad de revertir una frase determinada. En el ensayo dedicado a la obra de Roberto Juarroz en $L a$ máscara, Sucre apunta: "Lo sagrado como lo humano — o al revés - no implica ninguna trascendencia ni una nueva divinización" (La máscara 244; 1. ${ }^{a}$ ed.). Y también, en ese mismo texto:

Lo que intenta esa transgresión es hallar en el lenguaje la relación entre el nombre y lo nombrado. Esa simple relación traerá consigo una nueva fundación del mundo y, por tanto, la conquista verbal de la realidad [...] ¿ O será al revés? ¿Será, más bien, o simultáneamente, la conquista de la palabra desde el mundo? (La máscara 252; 1. ed.)

En otros casos, Sucre invierte directamente la frase para dar con el sentido que quiere comunicar. Así, por ejemplo, afirma: "No el simple deseo de claridad, sino, más bien, la claridad como deseo" (La máscara 302; 2. ed.). O, en este otro: "Más que la perfecta armonía, se trata de la armonía de la perfección” (La máscara 314; 1. a ed.). En estos fragmentos, apreciamos claramente cómo el pensamiento de Sucre se ajusta a las estructuras del lenguaje y se sabe limitado por ellas: es plenamente consciente de que está tratando con signos y no con cosas. Además, al enfatizar el carácter material de la escritura, estos ejemplos dejan entrever que detrás de las palabras no hay nada. Lo mismo sucede cuando nuestro autor yuxtapone vocablos con un significante similar, pero con un significado diferente, como, por ejemplo, cuando dice: "Y creo también que en ello reside la tensión - el drama, la trama- de esta obra” (La máscara 72; 2. ed.). ${ }^{22}$ En este caso, como vemos, el parecido de la forma contrasta con la diferencia del sentido: así, nuestro autor exalta el valor material de las palabras y al mismo tiempo expresa un distanciamiento con respecto a ellas. Este desapego y esta ironía con respecto al lenguaje se aprecian asimismo en el empleo de paronomasias y aliteraciones, como en este ejemplo: "Por ello las imágenes en esta poesía nunca se extravian en la extravagancia; su misterio no excluye la exactitud de la formulación verbal" (La máscara 75; 2. ${ }^{\mathrm{e}} \mathrm{ed}$.). Si bien este recurso no es muy utilizado por Sucre, sí es revelador - junto con los otros procedimientos que acabamos de ver- de su actitud con respecto a las palabras. En efecto, también en este caso, la forma parecida contrasta con la variación del significado, por lo que el escritor pone de manifiesto la vacuidad que se halla detrás de los vocablos. Si bien es evidente que en la obra de Oliverio Girondo estos experimentos son más constantes y más extremos, lo que Sucre afirma sobre él puede servir para iluminar su propia actitud. El poeta argentino, nos dice Sucre,

se vale de los poderes mismos del idioma, como el continuo uso de las aliteraciones; pero estas analogías fonéticas no vienen a subrayar una analogía semántica, sino, por el contrario, estimulan la contradicción o, en último caso, parodian toda coherencia del significado. (La máscara 277; 1. ${ }^{\mathrm{a}} \mathrm{ed}$.)

Al poner de manifiesto la falta de sentido de los vocablos, nuestro autor busca recuperar la plenitud original del lenguaje y restaurar una palabra no corrompida por la historia.

La escritura crítica de Sucre presenta, pues, la misma oscilación entre "la fascinación y el rechazo" ( $L a$ máscara 255; $1 .^{\mathrm{a}}$ ed.) que él observaba en el escritor moderno: "Por una parte —decía-, quiere llevar al lenguaje a su máxima posibilidad expresiva; por la otra, tiene conciencia no sólo de la máxima imposibilidad de lograrlo, sino también del equívoco que encierra la expresividad misma” (La máscara 256-257; 1. ${ }^{a}$ ed.). Al ser consciente de que está tratando con palabras y no con la realidad, nuestro autor ajusta su discurso al modo de ser del lenguaje y mantiene una actitud de pasión y de crítica con respecto a él. Es, además, esta percepción de la escritura lo que le permite concebir el ensayo crítico como un sistema de continuidades parciales que oscila entre el movimiento y la fijeza y que se resuelve en un cuerpo total que reproduce la coherencia de la obra que estudia.

En conclusión, en este artículo hemos analizado los ensayos de La máscara, la transparencia a partir de la concepción sucreana de la crítica literaria. Sucre considera que la obra literaria es un sistema y que la crítica es el resultado de la fusión del intérprete y del texto literario que toma cuerpo en una nueva creación verbal. A partir de estos planteamientos del propio autor, hemos analizado las principales características de la escritura de la crítica. Primero, hemos analizado cómo en los ensayos de Sucre se aprecia una dialéctica entre el movimiento 
y la fijeza que tiende a convertir el texto crítico en un absoluto verbal. Después, hemos apreciado cómo, a raíz de la "conciencia del lenguaje", en los textos críticos de Sucre se advierte una ambivalencia de pasión y de crítica con respecto a la propia escritura. Vemos entonces que para Sucre la crítica no sería simplemente un texto sobre otros textos, sino un tejido que incorpora en su propio cuerpo la trama filosófica en que se funda.

\section{Referencias}

Gomes, Miguel. Poéticas del ensayo venezolano del siglo XX. Universidad Católica Cecilio Acosta / Universidad del Zulia, 2007.

Montaigne, Michel de. Ensayos escogidos. UNAM, 1997.

Paz, Octavio. Los hijos del limo. Del romanticismo a la vanguardia. Seix Barral, 1974.

--.. "El mono gramático". Octavio Paz. Obra poética (1935-1998). 2. a ed. 1970. Galaxia Gutenberg, 2004, pp. 533-617.

Pozuelo-Yvancos, José María. "El género literario ensayo". El ensayo como género literario, editado por Vicente Cervera, Universidad de Murcia, 2005, pp. 179-191.

Rivera, Francisco. “Guillermo Sucre y la poesía latinoamericana”. Inscripciones. Fundarte, 1981.

Sucre, Guillermo. "Entretextos". En el verano cada palabra respira en el verano. Alfa, 1976.

--.. "Inscripciones, de Francisco Rivera". Vuelta, 1982, pp. 39-41.

--. La máscara, la transparencia. $1^{a}$ ed., Monte Ávila, 1975.

---La máscara, la transparencia. 2a ed., Fondo de Cultura Económica, 1985.

---. "Poesía Crítica: Lenguaje y silencio". Revista Iberoamericana, vol. 37, n. ${ }^{\text {os }}$ 76-77, julio-diciembre de 1971, pp. 575-597.

---. "Poesía hispanoamericana y conciencia del lenguaje”. Eco, n. ${ }^{\circ} 200,1978$, pp. 608-633.

---. "Ramos Sucre. La pasión por los orígenes". Obra poética completa, Fondo de Cultura Económica, 1999, pp. 9-38.

\section{Notas}

* Artículo de reflexión.

1 La conciencia de este cambio radical es ya patente en la obra de Montaigne. En el prefacio a los Essais, titulado "El autor al lector”, el escritor bordelés indicaba que antes que el tema, lo que importa es el sujeto, su visión. Con ello quería decir que importan menos los temas que la perspectiva del autor ante ellos: "Si yo hubiere pretendido buscar el favor del mundo, me hubiera engalanado con prestadas hermosuras; pero no quiero sino que se me vea en mi manera sencilla, natural y ordinaria, sin estudio ni artificio, porque sólo me pinto a mí mismo" (Montaigne 31). Así mismo, en el capítulo "Del desmentir" Montaigne apuntaba: "No hice tanto mi libro como mi libro me hizo a mí; éste es consustancial a su autor [...]: parte de mi vida y no de una ocupación y fin terceros y extraños, como todos los demás libros” (214). Como indica Pozuelo-Yvancos, en este fragmento se aprecia claramente cómo el escritor es consciente de que "yo y libro forman una unidad indisoluble, plenamente consciente, en el que el modelo de la escritura, tentativa, ensayo de explicación, perspectiva, crea al propio sujeto y lo convierte en medida de las cosas" (186). Como el asunto encarna en una forma, en una escritura, se produce una fusión entre el sujeto y el objeto y el ensayo deviene en el espacio de una presencia.

2 La escritura crítica de nuestro autor es la encarnación del presente perpetuo en el que se funden el objeto y la mirada crítica en una vivencia original del lenguaje. Con palabras del propio Sucre, "en la relación entre obra y mirada crítica todo tiende a fundarse - para decirlo con una imagen de Octavio Paz - en un presente perpetuo: instante absoluto que depende de ser relativo, y viceversa" (Sucre, "Poesía hispanoamericana" 608). A este respecto, conviene recordar que, al igual que en el caso de la lírica, la "tensión discursiva" del ensayo asume "una temporalidad del Discurso que emerge como fuerza ejecutiva en el presente de su formulación y cobra desde ese presente toda su fuerza” (Pozuelo-Yvancos 187).

3 Sucre advertía esta misma dialéctica en la obra de Octavio Paz: "Las recurrencias no sólo son importantes en Paz porque muestren su pasión constructiva; lo son también, y, sobre todo, porque él es un poeta de las recurrencias. Quiero decir: su obra es recurrente porque para él, el universo mismo lo es. La dialéctica entre el movimiento y la fijeza no es sólo un tema en su obra; llega a constituirse en su estructura misma y, por tanto, en la visión del mundo que ella encierra. 'En perpetuo cambio, la poesía no avanza', afirma Paz. Pero recurrencia no quiere decir simple repetición. En Paz no se prolonga sino 
lo que, en sí mismo, es fuente de intensidad - de vivacidad, como él dice” (Sucre, La máscara 209; 1. ª ed.). También en Piedra de Sol nuestro autor aprecia una dialéctica similar: "Si la concepción del poema es la del tiempo cíclico, lo cual supone una relación mutua entre el movimiento y la fijeza, esa relación está encarnada en las formas mismas del poema. Este se inicia con los versos arriba citados y concluye con los mismos: la repetición sugiere, por supuesto, el desarrollo de un ciclo que se cierra y a la vez se abre [...]. En los tres primeros versos del pasaje, las imágenes combinan el movimiento y la fijeza: algo fijo (árbol bien plantado) que se mueve (mas danzante); los tres siguientes, en cambio, ponen en marcha el movimiento mismo, que toma la imagen del río: de manera inversa, es ahora el movimiento el que tiende a la fijeza: progresa regresando, se va haciendo circular y así llega a un final que es también un comienzo" (Sucre, La máscara 222; 1. ${ }^{\mathrm{a}}$ ed.).

4 A no ser que se indique lo contrario, las cursivas son nuestras.

5 En este sentido, parece que la concepción de la escritura de Sucre se acerca asimismo a la de Lezama Lima: “'Como la fresa respira hilando su cristal', es uno de los versos de 'Muerte de Narciso'. La materia que, en su proceso mismo de gestación, va simultáneamente cristalizando. Tras el 'verismo' de esta imagen se abre otra percepción más penetrante: cámbiese el vocablo fresa por (tan próximo, ¿no?) frase, y se tendrá la mejor metáfora de lo que es el lenguaje de la poesía para Lezama: un debate entre la fijeza y la evaporación. La poesía, en efecto, ya lo hemos visto, es un enemigo rumor, devora por su propia fascinación y continuamente se nos escapa. El poema, por tanto, no puede ser una mera sucesión de metáforas, sino, además, la creación de un cuerpo resistente, no evanescente, que es la imagen total” (La máscara 200; 1. ${ }^{a}$ ed.).

6 En otra parte afirma, también a propósito de Borges, que "el pero [...] es el signo que relativiza lo que parece absoluto,

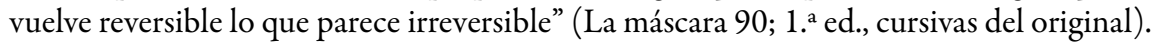

7 Miguel Gomes señala que "el ritornello" es "el método de exposición preferido en el ensayo, que se construye más por agregación que por desarrollo lógico. Se asumen y reasumen premisas; los temas —claros, lúcidos, eso sí- son sometidos a variaciones sutiles o manifiestas" (Gomes 194). Por su parte, Francisco Rivera indica que La máscara, la transparencia es fiel a su "método de temas y variaciones", y afirmaba también que la lectura de Sucre es "circular", puesto que en ella "un tema aparece, desaparece y repentinamente vuelve a aparecer, tal como por fin en sí mismo el incansable lector lo transforma, es imposible establecer una progresión espacio-temporal: la forma de la lectura envuelve lo leído tan íntimamente que sería una proeza separarlos" (Rivera 23, 25).

8 Estas estructuras que vemos en Sucre son constantes también en Octavio Paz, y es de él de quien nuestro autor las toma. Como los ensayos del mexicano nos muestran también el proceso de un pensamiento pensándose, en ellos se emplean las mismas fórmulas aditivas y contraargumentativas. En la escritura de Paz son frecuentes también las aposiciones (introducidas por dos puntos, o por punto y seguido) que explican o aclaran el sentido de una frase anterior. Esta cita que copiamos a continuación ejemplifica ambos aspectos: "El romanticismo — dice el maestro de Guillermo Sucre-fue un movimiento literario, pero asimismo fue una moral, una erótica y una política. Si no fue una religión fue algo más que una estética y una filosofía: una manera de pensar, sentir, enamorarse, combatir viajar. Una manera de vivir y una manera de morir" (Paz, Los hijos 89). Ambos mecanismos se ven también en este otro ejemplo: "La analogía concibe al mundo como ritmo: todo se corresponde porque todo ritma y rima. La analogía no sólo es una sintaxis cósmica: también es una prosodia" (Paz, Los hijos 95).

9 La cursiva referente al título de la obra de Vallejo aparece en el original. Esta estructura también aparece en la obra de Paz. Por ejemplo: "Fin de un período o anuncio de otro, Bécquer y Rosalía viven entre dos luces; quiero decir: no constituyen una época por sí solos, no son ni el romanticismo ni la poesía moderna” (Paz, Los hijos 118).

10 Este procedimiento lo emplea también Paz: “Tentativa de la imaginación poética por repoblar las almas que había despoblado la razón crítica, búsqueda de un principio distinto al de las religiones y negación del tiempo fechado de las revoluciones, el romanticismo es la otra cara de la modernidad: sus remordimientos, sus delirios, su nostalgia de una palabra encarnada" (Paz, Los hijos 119). Así mismo: "Modernidad antimoderna, rebelión ambigua, el modernismo fue un antitradicionalismo y, en su primera época, un anticasticismo: una negación de cierta tradición española” (Paz, Los hijos 130).

11 Aunque en los ensayos de Paz no hemos encontrado estructuras tan sorpresivas como en los de Sucre, es evidente que muchas veces nombra una idea polémica y comienza a tejer el discurso a partir de ella. Por ejemplo: "La modernidad es una separación. Empleo la palabra en su acepción más inmediata” (Paz, Los hijos 49).

12 A propósito de "Piedra de Sol", Sucre indica: "Paz tiene una concepción rítmica de la metáfora: una llama a otra que a su vez llama a otra, en un juego sucesivo de des- y encadenamientos; además, esas metáforas se diseminan a todo lo largo del poema: aparecen, desaparecen y reaparecen como verdaderas claves conductoras. Podría decirse que es a través de ellas como se van delineando y las diversas secuencias que lo constituyen" ( La máscara 223; 1. ed.).

13 En los ensayos de Paz también se aprecia esta estructuración. Como ejemplo de la recurrencia de una frase que sirve para dar cohesión a la escritura podemos citar, por ejemplo, el fragmento 4 de El mono gramático, que se organiza sobre la repetición de la frase "La fijeza es siempre momentánea" (547 y ss.). En otras ocasiones, Paz retoma también una idea que había mencionado previamente para completarla con nuevas ideas. Así, primero afirma: "Lo moderno no se caracteriza únicamente por su novedad, sino por su heterogeneidad. Tradición heterogénea o de lo heterogéneo, la 
modernidad está condenada a la pluralidad: la antigua tradición era siempre la misma, la moderna es siempre distinta”. Y dos páginas después recupera esa misma idea: "Dije que lo nuevo no es exactamente lo moderno salvo si es portador de la doble carga explosiva: ser negación del pasado y ser afirmación de algo distinto" (Paz, Los hijos 16, 18). Otro ejemplo similar es el siguiente. En un momento dado Paz afirma: "No es menos significativo que entre las obras centrales del verdadero romanticismo francés se encuentre Aurélia, la novela de Nerval, y un puñado de narraciones fantásticas de Charles Nodier”. Más adelante, al inicio de un nuevo párrafo, el escritor mexicano rescata, para completarla, una idea previa: "Escribí más arriba: el verdadero romanticismo francés. Hay dos: uno el de los manuales e historias de la literatura, está compuesto por una serie de obras elocuentes, sentimentales y discursivas que ilustran los nombres de Musset y Lamartine; otro, que para mí es el verdadero, está formado por un número muy reducido de obras y de autores: Nerval, Nodier, el Hugo del período final y los llamados 'pequeños románticos”' (Paz, Los hijos 98).

14 Esta misma organización binaria del texto la vemos también en Octavio Paz: "En la concepción de Baudelaire aparecen dos ideas. La primera es muy antigua y consiste en ver al universo como un lenguaje. No un lenguaje quieto sino en movimiento". Y en la página siguiente: "No es menos vertiginosa la otra idea que obsesiona a Baudelaire: si el universo es una escritura cifrada, un idioma en clave, ‘qué es el poeta, en el sentido más amplio, sino un traductor, un descifrador?"' (Paz, Los hijos 105-106).

15 La confirmación de que el absoluto de la escritura quiere reproducir el de la obra estudiada nos llega cuando advertimos que en ciertos momentos la continuidad del discurso se quiebra. Sabemos que para Sucre la obra es una relación necesaria entre lo que se dice y la manera de decirlo, y que este vínculo está en el origen de la continuidad discursiva que sus escritos quieren reproducir. Cuando el crítico se centra en rasgos puramente formales, la continuidad ética y estética de la obra se rompe y, por lo tanto, la escritura crítica no tiene más remedio que excluir esta enumeración del discurrir como si se tratara de una serie de hilos sueltos que exceden la tela de la escritura (y de la obra). Esto sucede precisamente cuando Sucre enumera rasgos puramente formales de una obra determinada (lo que sucede en La máscara 75, 118-119, 283-284; 1. ${ }^{\text {a ed.). }}$.

16 A este respecto, nuestro autor señalaba: "La lectura nace de la pasión de un lector, pero esta pasión se subordina a otra mayor, que es la fidelidad a una determinada idea de la literatura" (Sucre, "Inscripciones" 41).

17 Esta forma de establecer parecidos y diferencias, como ya sabemos, Guillermo Sucre la tomaba de Octavio Paz. Por ejemplo: "La figura de Fourier es central lo mismo en la historia de la poesía francesa que en la del movimiento revolucionario. No es menos actual que Marx (y sospecho que empieza a serlo más). Fourier piensa, como Marx, que la sociedad está regida por la fuerza, la coerción y la mentira, pero, a diferencia de Marx, cree que lo que une a los hombres es la atracción apasionada, el deseo" (Paz, Los hijos 102).

18 Asimismo, Sucre establece un vínculo entre Martí y los pintores impresionistas: "Si no con los mismos dones de Darío, cultivó las combinaciones sensoriales y, sobre todo, tuvo conciencia de la luz en el poema, tal como los pintores impresionistas. ¿No había escrito un admirable ensayo sobre este movimiento?” ( La máscara 32; 1. ed.). Igualmente, indica que, al formular el creacionismo, Huidobro "no hacía más que identificarse con una tradición estética muy anterior - Leonardo: la pintura es una cosa mental—, que resurgía y se intensificaba en el arte contemporáneo” ( La máscara $101 ; 1 .^{\mathrm{a}} \mathrm{ed}$.).

19 Sucre identifica con el lenguaje tanto la imaginación como el deseo; por eso, en un ensayo sobre Huidobro, afirma: "El poeta busca crear un mundo desde su visión, no reproducir otro; no el mundo que existe, sino el que debiera existir, dice Huidobro. Ese mundo no está edificado, por supuesto, sobre la ética: ha de estar regido por la imaginación y el deseo, por el lenguaje" ( La máscara 108; 1. ed.).

20 En un texto que escribió a propósito de este tema en la poesía hispanoamericana, Guillermo Sucre indicaba que "el silencio" es "fascinación por el lenguaje, búsqueda de la Palabra", y aclaraba que "esa fascinación" implicaba "la exaltación de lo verbal" y la "reconquista de la energía original del lenguaje" (Sucre, "Poesía crítica” 593-594). En ese mismo ensayo dice: "El poeta habla sobre el silencio desde el silencio. El silencio es lenguaje, no simple mutismo o mero callarse; presencia de la palabra, no su ausencia" (Sucre, "Poesía crítica" 592). Del mismo modo, después de citar esta conocida sentencia de Paz ("Enamorado del silencio, al poeta no le queda más recurso que hablar") nuestro autor señalaba: "Ni inconsecuencia ni simple paradoja, mucho menos desilusión: esta frase de Paz encierra, más bien, otro sentido, que es una doble metáfora. Hablar a partir de la conciencia que se tiene del silencio, es ya hablar de otro modo: al reconocer sus límites, el lenguaje puede recobrar al mismo tiempo su intensidad" ( La máscara 339; 1. ${ }^{\mathrm{e}} \mathrm{ed}$.). En estos dos fragmentos que hemos citado se advierte que Sucre considera que el silencio es una parte constitutiva del lenguaje; resulta imprescindible, por lo tanto, para que la palabra pueda recuperar su energía original, gastada por el uso y usurpada por el poder.

21 Este rasgo de estilo es también propio de los ensayos de Octavio Paz. Por ejemplo: "La reforma de la prosodia culmina en dos extremos contradictorios: los ritmos rotos y vivaces de Laforgue y Corbière y la partitura-constelación de $U n$ coup de dés. Los primeros influyeron profundamente en los poetas de las dos Américas: Lugones, Pound, Eliot, López Velarde; con el segundo nace una forma que no pertenece ni al siglo XIX ni a la primera mitad del XX, sino a nuestro tiempo" (Paz, Los hijos 98). 
22 Este recurso aparece también en Paz: "Poesía rimada y ritmada, no la prosa coloquial y viva, fuente de poesía, sino la oratoria y el discurso intelectual” (Paz, Los hijos 97). Otro ejemplo puede ser: "A su vez, la tradición ocultista de los siglos XVII y XVIII se entronca con varios movimientos de crítica social y revolucionaria, simultáneamente libertaria y libertina" (Paz, Los hijos 101).

\section{Licencia Creative Commons CC BY 4.0}

Cómo citar este artículo: Antzus Ramos, Ioannis. "El estilo de la crítica literaria en La máscara, la transparencia". Cuadernos de Literatura, vol. 25, 2021. https://doi.org/10.11144/Javeriana.cl25.eclm 